\title{
Preventive intervention for depression in children, adolescents and adults
}

\author{
Intervenția preventivă a depresiei la copii, adolescenți şi adulți \\ Ana Maria Alexandra STĂNESCU ${ }^{1}$, Anca Angela SIMIONESCU ${ }^{2,3}$, loana Veronica GRĂJDEANU ${ }^{1}$, \\ Mira FLOREA ${ }^{4}$
}

${ }^{1}$ Disciplina Medicină de familie, Universitatea de Medicină și Farmacie „Carol Davila“, București, România

${ }^{2}$ Departamentul Obstetrică-Ginecologie, Spitalul Clinic Filantropia, București, România

${ }^{3}$ Disciplina Obstetrică-Ginecologie, Universitatea de Medicină și Farmacie „Carol Davila",

București, România

${ }^{4}$ Disciplina Medicină de familie, Universitatea de Medicină și Farmacie „luliu Hațieganu“,

Cluj-Napoca, România

\begin{abstract}
Depression is a common mental disorder associated with increased morbidity and mortality. Depressive disorders usually occur around the age of 20. However, symptoms may appear earlier, even during childhood. Depressive episodes can be repetitive or chronic, affecting the individual's entire life. Primary prevention of unipolar depressive disorder is a potential strategy to stop or at least reduce the severity or delay the onset of a disorder. Primary preventive interventions are an ideal, modern and future approach that can have many benefits both in terms of population health and economic.
\end{abstract}

Keywords: depression, prevention, children, adolescents, adults

\section{REZUMAT}

Depresia este o tulburare mentală frecventă, asociată cu creșterea morbidității și mortalității. Tulburările depresive apar de obicei în jurul vârstei de 20 de ani. Cu toate acestea, simptomatologia poate să apară mai devreme, chiar în timpul copilăriei. Episoadele depresive pot fi repetitive sau pot deveni cronice, afectând individul întreaga viață. Prevenția primară a tulburărilor depresive unipolare este o strategie potențială pentru a opri sau, cel puțin, a reduce severitatea sau a întârzia apariția unei tulburări. Intervențiile preventive primare reprezintă o abordare ideală, modernă și de viitor ce poate avea numeroase beneficii atât pe planul sănătății populației, cât și pe plan economic.

Cuvinte cheie: depresie, prevenție, copii, adolescenți, adulți

\section{INTRODUCERE}

Depresia este o tulburare mentală frecventă, asociată cu creșterea morbidității și mortalității. Simptomele depresive, caracteristicile esențiale ale tulburărilor de- presive, pot să apară în întregime sau atenuate [1,2]. Tulburările depresive apar de obicei în jurul vârstei de 20 de ani. Cu toate acestea, simptomatologia poate sa apară mai devreme, chiar în timpul copilăriei [3]. 
Episoadele depresive pot fi repetitive sau pot deveni cronice, afectând individul întreaga viață. Se preconizează că tulburările depresive vor fi cea mai mare cauză de boală la nivel mondial până în 2030 [4].

Psihiatria modernă promovează prevenția ca abordare de bază în managementul tulburărilor mintale. Prevenția primară a tulburărilor depresive unipolare este o strategie potențială pentru a opri sau, cel puțin, a reduce severitatea sau a întârzia apariția unei tulburări [5]. Pentru ca prevenirea primară a depresiei să fie implementată în practica clinică, este necesară implicarea medicului de prim contact cu pacientul, și anume medicul de familie.

\section{INTERVENȚIA PREVENTIVĂ LA COPII ȘI ADOLESCENȚI}

Studiile arată că intervențiile preventive efectuate la o vârstă fragedă ar putea avea un impact deosebit de mare asupra prevenirii apariției depresiei [6].

Un studiu recent ce a inclus 46 de metaanalize, cu un total de 286.429 de persoane, a arătat că, la copii și adolescenți, 83,3\% dintre intervențiile pentru simptomele depresive și 70\% dintre intervențiile pentru debutul tulburărilor depresive au fost eficiente [7].

O problemă cu privire la copii și adolescenți este reprezentată de siguranța antidepresivelor, fiind puține date disponibile cu privire la siguranța medicamentelor psihotrope la copii și adolescenți cu tulburări mintale, ceea ce a determinat o mai mare predilecție către intervențiile psihosociale în această grupă de vârstă [8].

Din puținele dovezi disponibile, medicamentele antidepresive au demonstrat că reduc recidiva/recurența depresiei la copii și adolescenți care au suferit deja un episod depresiv [9]. Cu toate acestea, frecvent studiile clinice exclud copiii și adolescenții, determinând ca dovezile actuale să fie insuficiente pentru a evalua echilibrul beneficii/riscuri pentru medicația psihofarmacologică.

Având în vedere toate acestea, intervențiile psihosociale preventive, în special intervențiile psihoterapeutice, devin o țintă importantă la copii și adolescenți. Unele dintre tipurile de intervenții posibile sunt redate în Tabelul 1.

TABEL 1. Tipuri de intervenții la adolescenți și copii

\begin{tabular}{|c|c|c|}
\hline & Tip de intervenție & Referință / An \\
\hline 1 & $\begin{array}{c}\text { Terapia cognitiv- } \\
\text { comportamentală (TCC) }\end{array}$ & $\begin{array}{c}\text { Rasing și colaboratorii [10] } \\
2017\end{array}$ \\
\hline 2 & $\begin{array}{c}\text { Terapia cognitiv- } \\
\text { comportamentală de grup }\end{array}$ & $\begin{array}{c}\text { Ssegonja și colaboratorii [11] } \\
2019\end{array}$ \\
\hline 3 & Strategii metacognitive & Kajka și Kulik [12] \\
& 2021 \\
\hline 4 & $\begin{array}{c}\text { Strategii metacognitive } \\
\text { desfășurate în medii } \\
\text { școlare }\end{array}$ & $\begin{array}{c}\text { Werner-Seidler și } \\
\text { colaboratorii [13] } \\
\end{array}$ \\
\hline
\end{tabular}

Se pare că dovezile sunt mai numeroase în ceea ce privește intervențiile psihoterapeutice specifice țintei, în comparație cu intervenții psihosociale [14,15].

Catalan și colaboratorii au publicat o metaanaliză în anul 2020 cu privire la prevenirea psihozei la copii și adolescenți, concluzionând că nu există suficiente dovezi pentru a recomanda o intervenție preventivă specifică [16].

Deși se consideră că activitatea fizică ar avea beneficii pozitive asupra sănătății fizice, dar și mentale, nu există suficiente date pentru a recomanda acest tip de intervenție ca intervenție de primă linie în prevenția depresiei la copiii și adolescenții la risc [17]. Cu toate acestea, activitatea fizică poate fi o intervenție promițătoare pentru promovarea generală a sănătății mintale [18].

Se consideră că depistarea riscului de depresie (pacienți cu simptome depresive vagi sau cu factori de risc pentru depresie) este de multe ori mai dificilă decât depistarea riscului de psihoză [19].

Intervențiile psihosociale pot fi oferite copiilor și adolescenților cu risc în funcție de circumstanțele individuale și de indicațiile medicale, dar și în funcție de preferințele pacientului.

Intervențiile psihologice și educaționale pentru a preveni depresia în îngrijirea primară par să aibă un efect pozitiv, medicii de familie putând să implementeze programe și intervenții pentru prevenirea depresiei [20].

\section{INTERVENȚIA PREVENTIVĂ LA ADULȚI}

Se consideră că, în ceea ce privește tratamentele psihofarmacologice, riscurile depășesc beneficiile pentru persoanele fără risc anterior de a dezvolta depresie. Tratamentele psihofarmacologice în general pot fi luate în considerare la persoanele cu simptome depresive vagi și la persoanele cu afecțiuni medicale.

Sa arătat că utilizarea antidepresivelor a redus incidența depresiei și a îmbunătățit simptomatologia depresiei, în special cele utilizate pe o durată a tratamentului $\geq 1$ an la persoanele cu accident vascular cerebral [21,22].

Și la adulți, având în vedere necesitatea personalizării tratamentului, decizia medicului curant și preferințele pacientului, intervențiile psihosociale - inclusiv psihoeducația sau intervențiile psihologice precum terapia cognitiv-comportamentală, terapia cognitiv-comportamentală de grup și terapia interpersonală - pot reprezenta o modalitate de prevenție a depresiei la adulți, în special la adulții tineri, care au mai multe șanse să beneficieze de aceste tipuri de intervenții.

Sa demonstrat că, la persoanele fără risc anterior de depresie, intervențiile la locul de muncă au prevenit noi cazuri de depresie [23]. Tot în contextul locului de 
muncă, persoanele din domeniul sanitar s-au dovedit a fi la risc în contextul pandemic actual, fiind o populație țintă pentru abordări preventive, în special programe psiho-educative [24].

Incidența depresiei postpartum este de $12 \%$, iar prevalența generală a depresiei este de $17 \%$ la mamele sănătoase fără antecedente de depresie, fiind o necesitate implementarea abordărilor preventive în această perioadă [25]. Nu există o metaanaliză a intervențiilor farmacologice în perioada prenatală/perinatală pentru a preveni depresia, fiind foarte dificil de cuantificat în această populație raportul risc/beneficiu.

Intervențiile psihosociale pot fi oferite femeilor însărcinate, care resimt o îmbunătățire semnificativă după ce au primit intervenții psihosociale pentru simptome depresive, precum și pentru prevenirea tulburărilor depresive [26].

În general, se considera că intervențiile bazate pe exerciții fizice ar putea fi adecvate femeilor însărcinate fără un risc deosebit de mare de depresie, în timp ce psihoterapia ar putea fi oferită femeilor însărcinate cu risc ridicat.

\section{IMPLICAȚII GENERALE CU PRIVIRE LA INTERVENTุIILE PREVENTIVE}

Prevenția primară a depresiei este multidimensională, având efecte atât asupra apariției depresiei, asupra recidivelor viitoare, cât și asupra atenuării simptomatologiei pe termen mediu și lung $[27,28]$. Prevenția poate contribui la diminuarea riscului de apariție a depresiei, dar și a altor tipuri de tulburări mentale ce pot debuta cu simptomatologie depresivă, mai ales la per- soanele cu factori de risc [29]. Prevenirea primului episod de depresie este importantă și pentru prognosticul altor tulburări mentale [30].

În unele cazuri, poate fi dificil de realizat prevenția tulburărilor depresive, mai ales în cazul copiilor și adolescenților, la cei care prezintă comorbidități, cei cu tulburări cognitive sau în cazul consumului de substanțe [31]. Un alt impediment poate fi reprezentat de costul intervențiilor, mai ales cele care necesită interacțiunea față în față; acest impediment ar putea fi rezolvat prin telemedicină, cu ajutorul inteligenței artificiale [32]. Intervențiile preventive sunt în general bune din punct de vedere financiar, având în vedere costurile mari, pe termen îndelungat, ale terapiei depresiei.

Cercetările viitoare ar trebui să evalueze persistența și eficacitatea pe termen lung a intervențiilor preventive și a formatelor inovatoare de abordare, cum ar fi terapiile bazate pe internet și intervențiile bazate pe smartphone-uri [33]. De asemenea, cercetările viitoare ar trebui să evalueze ce intervenții particulare ar fi cele mai eficiente pentru fiecare grup populațional în parte.

\section{CONCLUZII}

Intervențiile preventive primare reprezintă o abordare ideală, modernă și de viitor care poate avea numeroase beneficii atât pe planul sănătății populației, cât și în plan economic. Eficacitatea acestor intervenții este în principal dovedită la persoanele cu factori de risc pentru depresie. Medicii de familie sunt în prima linie în ceea ce privește determinarea inițială a intervenției preventive.

Conflict of interest: none declared Financial support: none declared

\section{BIBLIOGRAFIE}

1. American Psychiatric Association. Diagnostic and statistical manual of mental disorders (Vol. 3). Washington, DC: Ed. American Psychiatric Association, 1980.

2. Salazar de Pablo G, Guinart D, Cornblatt BA, et al. Demographic and Clinical Characteristics, Including Subsyndromal Symptoms Across Bipolar-Spectrum Disorders in Adolescents. J Child Adolesc Psychopharmacol. 2020;30(4):222-234.

3. Fusar-Poli P. Integrated Mental Health Services for the Developmental Period (0 to 25 Years): A Critical Review of the Evidence. Front Psychiatry. 2019;10:355.

4. Lépine JP, Briley M. The increasing burden of depression. Neuropsychiatr Dis Treat. 2011;7(Suppl 1):3-7.

5. Fusar-Poli P, Bauer M, Borgwardt S, et al. European college of neuropsychopharmacology network on the prevention of mental disorders and mental health promotion (ECNP PMD-MHP). Eur Neuropsychopharmacol. 2019; 29(12):1301-1311.

6. Gladstone TR, Beardslee WR, O'Connor EE. The prevention of adolescent depression. Psychiatr Clin North Am. 2011;34(1):35-52.

7. Salazar de Pablo G, Solmi M, VaquerizoSerrano J, et al. Primary prevention of depression: An umbrella review of controlled interventions. J Affect Disord. 2021; 294:957-970.

8. Solmi M, Fornaro M, Ostinelli EG, et al. Safety of 80 antidepressants, antipsychotics, anti-attention-deficit/hyperactivity medications and mood stabilizers in children and adolescents with psychiatric disorders: a large scale systematic meta-review of 78 adverse effects. World Psychiatry. 2020; 19(2):214-232.

9. Cox GR, Fisher CA, De Silva S, et al. Interventions for preventing relapse and recurrence of a depressive disorder in children and adolescents. Cochrane Database Syst Rev. 2012;11:CD007504.

10. Rasing SPA, Creemers DHM, Janssens JMAM, et al. Depression and Anxiety Prevention Based on Cognitive Behavioral Therapy for At-Risk Adolescents: A Meta-Analytic Review. Front Psychol. 2017; 8:1066.

11. Ssegonja R, Nystrand C, Feldman I, Sarkadi A, Langenskiöld S, Jonsson U. Indicated preventive interventions for depression in children and adolescents: A meta-analysis and meta-regression. Prev Med. 2019 Jan;118:7-15. 
12. Kajka N, Kulik A. The Influence of Metacognitive Strategies on the Improvement of Reaction Inhibition Processes in Children with ADHD. Int $J$ Environ Res Public Health. 2021;18(3):878.

13. Werner-Seidler A, Perry Y, Calear AL, et al. School-based depression and anxiety prevention programs for young people: A systematic review and meta-analysis. Clin Psychol Rev. 2017;51:30-47.

14. Hetrick SE, Cox GR, Witt KG, et al. Cognitive behavioural therapy (CBT), third-wave CBT and interpersonal therapy (IPT) based interventions for preventing depression in children and adolescents. Cochrane Database Syst Rev. 2016; (8):CD003380.

15. Yap MBH, Morgan AJ, Cairns K, et al. Parents in prevention: A meta-analysis of randomized controlled trials of parenting interventions to prevent internalizing problems in children from birth to age 18. Clin Psychol Rev. 2016;50:138-158.

16. Taylor JH, Huque ZM. Commentary: Schizophrenia prevention and prodromal psychosis in children and adolescents. J Child Psychol Psychiatry. 2021; 62(5):674-676.

17. Ashdown-Franks G, Firth J, Carney R, et al. Exercise as Medicine for Mental and Substance Use Disorders: A Meta-review of the Benefits for Neuropsychiatric and Cognitive Outcomes. Sports Med. 2020;50(1):151-170.

18. Fusar-Poli P, Salazar de Pablo G, De Micheli $A$, et al. What is good mental health? A scoping review. Eur Neuropsychopharmacol. 2020;31:33-46

19. Salazar de Pablo G, Estradé A, Cutroni M, et al. Establishing a clinical service to prevent psychosis: What, how and when? Systematic review. Transl Psychiatry. 2021;11(1):43.

20. Conejo-Cerón S, Moreno-Peral P, Rodríguez-Morejón A, et al. Effectiveness of Psychological and Educational Interventions to Prevent Depression in Primary Care: A Systematic Review and Meta-Analysis. Ann Fam Med. 2017;15(3):262-271.

21. Gu J, Huang H, Chen K, et al. Are they necessary? Preventive therapies for post-stroke depression: A meta-analysis of RCTs. Psychiatry Res. 2020;284:112670.

22. Salter KL, Foley NC, Zhu L, et al. Prevention of poststroke depression: does prophylactic pharmacotherapy work? J Stroke Cerebrovasc Dis. 2013;22(8):1243-1251.

23. Bellón JÁ, Conejo-Cerón S, Cortés-Abela C et al. Effectiveness of psychological and educational interventions for the prevention of depression in the workplace: A systematic review and meta-analysis. Scand J Work Environ Health. 2019;45(4):324-332.

24. Salazar de Pablo G, Vaquerizo-Serrano J, Catalan A, et al. Impact of coronavirus syndromes on physical and mental health of health care workers: Systematic review and meta-analysis. J Affect Disord. 2020; 275:48-57.

25. Shorey S, Chee CYI, Ng ED, et al. Prevalence and incidence of postpartum depression among healthy mothers: A systematic review and meta-analysis. J Psychiatr Res. 2018;104:235-248.

26. Goodman SH, Cullum KA, Dimidjian S, et al. Opening windows of opportunities: Evidence for interventions to prevent or treat depression in pregnant women being associated with changes in offspring's developmental trajectories of psychopathology risk. Dev Psychopathol. 2018;30(3):1179-1196.

27. Ten Have M, de Graaf R, van Dorsselaer S, et al. Recurrence and chronicity of major depressive disorder and their risk indicators in a population cohort. Acta Psychiatr Scand. 2018;137(6):503-515.

28. Solmi M, Miola A, Croatto G, et al. How can we improve antidepressant adherence in the management of depression? A targeted review and 10 clinical recommendations. Braz J Psychiatry. 2021;43(2):189-202.

29. Oliver D, Reilly TJ, Baccaredda Boy O, et al. What Causes the Onset of Psychosis in Individuals at Clinical High Risk? A Meta-analysis of Risk and Protective Factors. Schizophr Bull. 2020;46(1):110-120.

30. Salazar de Pablo G, Guinart D, Cornblatt BA, et al. Demographic and Clinical Characteristics, Including Subsyndromal Symptoms Across Bipolar-Spectrum Disorders in Adolescents. J Child Adolesc Psychopharmacol. 2020;30(4):222-234.

31. Solmi M, Miola A, Croatto G, et al. How can we improve antidepressant adherence in the management of depression? A targeted review and 10 clinical recommendations. Braz J Psychiatry. 2021;43(2):189-202.

32. Nair U, Armfield NR, Chatfield MD, et al. The effectiveness of telemedicine interventions to address maternal depression: A systematic review and meta-analysis. $J$ Telemed Telecare. 2018;24(10):639-650.

33. Patoz MC, Hidalgo-Mazzei D, Blanc O, et al. Patient and physician perspectives of a smartphone application for depression: a qualitative study. BMC Psychiatry. 2021;21(1):65. 